\title{
The treatment of middle-third clavicle fractures: A paradigm shift
}

\author{
Justin H Bartley*1 \\ ${ }^{1}$ Department of Orthopedic Surgery, University of Colorado Health Science Center, Boulder, CO, USA
}

\section{Introduction}

Since the time of Hippocrates, clavicle fractures have been considered a relatively benign entity that requires little more than neglect [1]. Recently, there has been a paradigm shift; lending serious consideration for operative care in the setting of middle third clavicle fractures and leading to a noticeable increase in the incidence of surgically treated middle-third clavicle fractures. The number of patients presenting with mid-shaft clavicle fractures has remained relatively constant but the incidence of operative fixation of clavicle fractures has increased by as much as $368 \%$ [2].

Any shift of this magnitude in the time-proven principles of fracture care is certain to attract attention and beg the question; are we operating unnecessarily? To truly establish an evidence-based approach to the management of middle-third clavicle fractures and understand the rising incidence of operatively treated clavicle fractures, the evolution of the recommended operative indications must be understood.

\section{A historical perspective}

Neer initially published a cohort of 2235 patients in 1960 that encouraged a conservative, non-operative approach to the treatment of middle third clavicle fractures; because non-operative management was associated with a non-union rate of $0.13 \%$ versus $4.6 \%$ in the 45 patients that were treated operatively [3]. This study stressed the importance of simple, conservative care in the setting of these injuries. Over time, additional literature regarding this area of interest hinted that non-operative management might not be 'best' for all mid-shaft clavicle fractures. For example, Robinson, et al. noted a non-union rate of $4.5 \%$ in their cohort of non-operatively treated middle third clavicle fractures; more importantly they established several significant risk factors associated with these non-unions including advancing age, female gender, displacement of the fracture, and the presence of comminution [4]. In 2005, a systematic review further stressed the importance of these risk factors by publishing a non-union rate of $15.1 \%$ in displaced, mid-clavicle fractures that were treated nonoperatively [5].

Over time, clinical and performance based outcomes were published on these patients following non-operative care. McKee, et al. reported residual disability in patients who underwent non-operative treatment of displaced mid-shaft clavicle fractures with Constant scores of 71 points and DASH scores of 24.6 points at 55 months after injury [6]. Objective shoulder strength testing in this same cohort noted significantly decreased strength and endurance in flexion, abduction, external rotation, and internal rotation of the shoulder [6]. In addition, several studies found that shortening of $14-20 \mathrm{~mm}$ at the sight of the fracture is associated with unsatisfactory results $[7,8]$.
In 2007, a multicenter, prospective, randomized clinical trial conducted by the Canadian Orthopedic Trauma Society (COTS) compared operative (ORIF) and non-operative (Sling) treatment in 132 patients with displaced mid-shaft clavicle fractures [9]. They found that in addition to overall satisfaction, Constant and DASH scores significantly increased with surgical treatment, while mean time to radiographic union, non-unions, and symptomatic malunions all decreased with surgery [9].

\section{Operative fixation modalities}

Various surgical treatment options are available, but middle-third clavicle fractures are typically treated with open reduction and internal plate fixation or intramedullary nail fixation. Open reduction with plate fixation allows for rigid fixation that enables early mobilization of the involved shoulder [7,10-12]. Intramedullary nailing offers a cosmetically appealing fixation technique at the cost of rotational and length stability [13-16]. Both fixation techniques have been reported to lead to faster mobilization of the involved extremity with faster return to sport [17-20]. A randomized control trial involving 68 athletes demonstrated better short-term mobility, improved strength, and quicker return-to sport if treated with an intramedullary fixation versus non-operative treatment [21].

\section{Rehabilitation}

There is not a consensus on the duration of immobilization or rehabilitation protocol following a clavicle fracture [7,22-26]. However, 12 athletes reportedly returned to training at 5.9 days and competition at 16.8 days following intramedullary nailing of displaced, middle third clavicle fractures [17]. In addition, an accelerated rehab protocol has been published that allowed a collegiate football player to pursue immediate active shoulder mobilization after surgery, obtain full strength and range of motion at 5 weeks post-op, and return to competition at post-op week 6 following open reduction with plate fixation of a comminuted, midshaft clavicle fracture [19].

\section{Conclusion}

In summary, cumulative evidence has led to relative operative indications for middle-third clavicle fractures that likely explain the increasing incidence in surgical treatment for mid-shaft clavicle fractures and the paradigm shift noted in the literature. These relative

Correspondence to: Justin $\mathrm{H}$ Bartley, Department of Orthopedic Surgery, University of Colorado Health Science Center, Boulder, CO, USA, E-mail: justin.h.bartley@gmail.com

Received: March 10, 2017; Accepted: March 30, 2017; Published: April 03, 2017 
indications include significant shortening $(>1.4-2 \mathrm{~cm})$, comminution, displacement $(>100 \%)$, cosmetic deformity, and poly-trauma situations [26]. The intended outcome is to maximize patient clinical (Constant, $\mathrm{DASH}$ ) and performance-based outcomes (strength, endurance); minimize time-to-union, non-unions, and malunions. The ultimate goal is to provide optimal outcomes with early return to activity for patients or at least allow patients to make a well-educated decision regarding operative versus non-operative management.

\section{References}

1. Adams F (1886) The genuine works of Hippocrates. New York: William Wood.

2. Micev AJ (2016) The rising incidence of operative treatment of mid-shaft clavicle fractures. Orthopedic \& Muscular System 5.

3. NEER CS 2nd (1960) Nonunion of the clavicle. J Am Med Assoc 172: 1006-1011. [Crossref]

4. Robinson CM, Court-Brown CM, McQueen MM, Wakefield AE (2004) Estimating the risk of nonunion following nonoperative treatment of a clavicular fracture. J Bone Joint Surg Am 86-86A: 1359-65. [Crossref]

5. Zlowodzki M, Zelle BA, Cole PA, Jeray K, McKee MD; Evidence-Based Orthopaedic Trauma Working Group (2005) Treatment of acute midshaft clavicle fractures: systematic review of 2144 fractures: on behalf of the Evidence-Based Orthopaedic Trauma Working Group. J Orthop Trauma 19: 504-507. [Crossref]

6. McKee MD, Wild LM, Schemitsch EH (2003) Midshaft malunions of the clavicle. $J$ Bone Joint Surg Am 85: 790-797. [Crossref]

7. Hill JM, McGuire MH, Crosby LA (1997) Closed treatment of displaced middle-third fractures of the clavicle gives poor results. J Bone Joint Surg Br 79: 537-539. [Crossref]

8. Lazarides S, Zafiropoulos G (2006) Conservative treatment of fractures at the middle third of the clavicle: the relevance of shortening and clinical outcome. $J$ Shoulder Elbow Surg 15: 191-194. [Crossref]

9. Canadian Orthopaedic Trauma Society (2007) Nonoperative treatment compared with plate fixation of displaced midshaft clavicular fractures. A multicenter, randomized clinical trial. J Bone Joint Surg Am 89: 1-10. [Crossref]

10. Kabak S, Halici M, Tuncel M, Avsarogullari L, Karaoglu S (2004) Treatment of midclavicular nonunion: comparison of dynamic compression plating and low-contact dynamic compression plating techniques. J Shoulder Elbow Surg 13: 396-403. [Crossref]

11. Mullaji AB, Jupiter JB (1994) Low-contact dynamic compression plating of the clavicle. Injury 25: 41-45. [Crossref]
12. Neer CS 2nd (1968) Fractures of the distal third of the clavicle. Clin Orthop Relat Res 58: 43-50. [Crossref]

13. Andermahr J, Jubel A, Elsner A, Johann J, Prokop A, et al. (2007) Anatomy of the clavicle and the intramedullary nailing of midclavicular fractures. Clin Anat 20: 48-56. [Crossref]

14. Golish SR, Oliviero JA, Francke EI, Miller MD (2008) A biomechanical study of plate versus intramedullary devices for midshaft clavicle fixation. J Orthop Surg Res 3: 28. [Crossref]

15. Rowe CR (1968) An atlas of anatomy and treatment of midclavicular fractures. Clin Orthop Relat Res 58: 29-42. [Crossref]

16. Thumroj E, Kosuwon W, Kamanarong K (2005) Anatomic safe zone of pin insertion point for distal clavicle fixation. J Med Assoc Thai 88: 1551-1556. [Crossref]

17. Jubel A, Andemahr J, Bergmann H, Prokop A, Rehm KE (2003) Elastic stable intramedullary nailing of midclavicular fractures in athletes. Br J Sports Med 37: 480483. [Crossref]

18. Meier C, Grueninger P, Platz A (2006) Elastic stable intramedullary nailing for midclavicular fractures in athletes: indications, technical pitfalls, and early results. Acta Orthop Belg 72: 269-275. [Crossref]

19. Rabe SB, Oliver GD (2011) Clavicular fracture in a collegiate football player: a case report of rapid return to play. $J$ Athl Train 46: 107-111. [Crossref]

20. Verborgt O, Pittoors K, Van Glabbeek F, Declercq G, Nuyts R, et al. (2005) Plate fixation of middle-third fractures of the clavicle in the semi-professional athlete. Acto Orthop Belg 71: 17-21. [Crossref]

21. Witzel K (2007) Intramedullary osteosynthesis in fractures of the mid-third of the clavicle in sports traumatology. Z Orthop Unfall 145: 639-642. [Crossref]

22. Lazarus MD (2002) Fractures of the clavicle. Rockwood and Green's fractures in adults. Ed. Heckman JD Bucholz RW. 5th. Philadelphia: Lippincott Williams \& Wilkins; 1041-1078

23. Nordqvist A, Petersson CJ, Redlund-Johnell I (1998) Mid-clavicle fractures in adults end result study after conservative treatment. J Orthop Trauma 12: 572-576. [Crossref]

24. Andersen K, Jensen PO, Lauritzen J (1987) Treatment of clavicular fractures. Figureof-eight bandage versus a simple sling. Acta Orthop Scand 58: 71-74. [Crossref]

25. Eskola A, Vainionpää S, Myllynen P, Pätiälä H, Rokkanen P (1986) Outcome of clavicular fracture in 89 patients. Arch Orthop Trauma Surg 105: 337-338. [Crossref]

26. van der Meijden OA, Gaskill TR, Millett PJ (2012) Treatment of clavicle fractures: current concepts review. J Shoulder Elbow Surg 21: 423-429. [Crossref]

Copyright: (2017 Bartley JH. This is an open-access article distributed under the terms of the Creative Commons Attribution License, which permits unrestricted use, distribution, and reproduction in any medium, provided the original author and source are credited. 